\title{
A LA LUZ DEL MEDITERRÁNEO. CULTURAS, CIVILIZACIONES Y SOCIEDADES
}

\section{Benjamín Oltra*}

\author{
"Dort im schweigenden Tal, an Tempes hängenden Felsen, \\ Will ich wohnen, mit euch, dort oft, ihr herrlichen Namen!'( *) \\ (Friedrich Hölderlin, Der Archipielagus-ca.1805)
}

Estas páginas están engarzadas en forma de un argumento narrativo de Sociología literaria. En honor a lo deslumbrante del mundo que narramos (ex Oriente lux), he decidido presentar dicho argumento siguiendo los tiempos de un cuarteto de cámara.

\section{Inicio: es preciso un argumento narrativo para dibujar lo realmente fascinante}

No debemos dejarnos raptar por la belleza cultural de esa arrolladora onda civilizatoria que es el Mediterráneo, si queremos entenderlo con cierta finura, sin lugares comunes; pero no es aconsejable que la investigación, y su argumento, prescindan de la narración. Ser mediterráneo, si es que tal cosa puede decirse, es una de las diversas maneras culturales y civilizadas de simbolizar y encarnar la naturaleza, el paisaje, el tiempo, la conciencia, la familia, los otros, lo transcendente, el drama de la condición humana, el estilo de vida y los hábitos que propician las cosas buenas de la vida, a la luz de este pequeño lago de sueños y de tragedia. Ser mediterráneo es un acervo de formas religiosas y profanas de vivir sumidos, consciente o inconscientemente, en la corriente estética y física de un mar literariamente real o realmente literario, por excelencia, cuyo argumento fue soñado por el enigmático Heráclito de Éfeso (544- 476 a. C.) en su máxima "panta rei": la realidad es un incesante fluir activo, creativo y contemplativo; diríase que de obligaciones y devociones.

\footnotetext{
*Catedrático de Sociología de la Cultura en el Departamento de Sociología I y Teoría de la Educación de la Universidad de Alicante, y vicepresidente de la Fundación «Ciencias Sociales y Mundo Mediterráneo», con sede en Altea.
} 


\section{Andante: cuando la vida imita al arte}

Bien podemos imaginar el Mediterráneo como una dilatada y vasta sinfonía en un antiquísimo espacio / tiempo natural; un ecosistema marino dramático representado por creativas, expansivas y declinantes culturas, civilizaciones y sociedades que se mezclan, fecundan, recrean y destruyen. Spengler, Toynbee, Sorokin y Braudel hablaron de ello con auténtica auctoritas intelectual. Pero fue el bueno de Oscar Wilde el que decretó que la vida imita al arte en mayor medida de lo que el arte imita a la vida. Así ocurre en el Mediterráneo: su turbulenta duración, "toujours recomencée", como lo viera Paul Valéry en su luminoso Le cimetière marin (1920), llena de genio, mas también, en ocasiones, de ruido y de furia, es la encarnación de la leyenda etíope y egipcia del "Ave Fénix", el águila roja, azul, púrpura y oro, según cuenta Heródoto, que renace de sus cenizas cada quinientos años. El Cuadro 0 (El Mediterráneo: esquema narrativo) plasma esta idea.

Trátase, como puede apreciarse, de un sencillo esquema narrativo, en parte literario, en parte investigador, para orientarse en un auténtico laberinto, un proceloso piélago de ciudades, palacios, templos, santuarios, teatros, necrópolis y paisajes mágicos, donde los seres humanos, desde hace 150.000 años, descubren, crean y modelan la Cultura y, culturalmente convertidos y simbolizados en pueblos y civilizaciones, desde hace 11.000 , integradas por hombres y mujeres de carne y hueso, y por héroes, profetas, santos y dioses(con sus figuras contrarias y míticas), van tejiendo y destejiendo todas las formas económicas, sociales, políticas, culturales, urbanas, que conducen el infinito delta de culturas al lago de nuestras sociedades, sistemas de bienestar, convivencia, ciudadanía y privacidad en que el fecundo Mediterráneo ha convertido a Occidente y, por ahora, sólo a una cuarta parte del propio escenario mediterráneo. Ese "drama", y sus reflujos, tiene su planteamiento, cenit y desenlace: un movimiento ondulatorio complejo en la Antigüedad (9000 a 900 a C), la era Clásica ( 900 a C a 476 d C), el Medioevo (500 a 1453) y el mundo moderno (1492 a la actualidad). En semejante tiempo o longue durée dramáticos, los grandes actores del Mediterráneo forman una red o círculo creativo, humano, étnico, económico, civilizatorio y de poder que integra a personalidades, grupos y pueblos que perfilaron las culturas en sentido creador, religioso, moral, material y de estilos de vida, comunidades y estructuras sociales. Representamos tan compleja y laberíntica "escenografía" en la unidad de acción y de creación cultural, en un sistema de ciudades, que denominamos "civilización", fundamento temporal de las sociedades actuales. Hemos tipificado las civilizaciones mediterráneas en 26 grandes unidades, grandes conjuntos ecoculturales, religiosos, económicos y políticos que se proyectan y actúan como "imperios". La magnífica sucesión de esas 26 formas civilizatorias creadoras nos presenta un "argumento"en el tiempo, trama narrativa que hemos y tipificado en el Cuadro 0, en el Mapa 1 (Sucesión de Civilizaciones) y en la tipología del Cuadro 1. 
Cuadro 0

\section{EL MEDITERRÁNEO: CULTURAS, CIVILIZACIONES Y SOCIEDADES. ESQUEMA NARRATIVO}

Argumento

$\begin{array}{llll}\begin{array}{l}\text { Civilizaciones } \\ \text { antiguas }\end{array} & \begin{array}{l}\text { Civilizaciones } \\ \text { clásicas }\end{array} & \begin{array}{l}\text { Civilizaciones } \\ \text { medievales }\end{array} & \begin{array}{l}\text { Civilizaciones } \\ \text { modernas }\end{array}\end{array}$

Planteamiento

*Creciente fértil

*Sumer

*Akkad

*Egipto

Cenit

*Egipto

*Levante

*Euroantiguos

*Hitita

*Babilonia

*Asiria

Desenlace

*Israel
*Fenicia

*Minos

*Micenas

*Hélade

*Etruria

*Persia

*Roma
*Bizancio

*Oleadas de euroantiguos

*Judía

*Eurocristiana

*Bizancio

*Islám
*Reinos/Estados eurocristianos en el Renacimiento

*Imperio Otomano
*Reinos/Estados

eurocristianos en el Barroco y la Ilustración *ImperioOtomano

Fuente: Prof. Benjamín Oltra. Programa de Sociología y Cultura del Mundo Mediterráneo, Dpto. de Sociología I, Universidad de Alicante; y Fundación Ciencias Sociales y Mundo Mediterráneo, Altea. 


\section{VEINTITRÉS CIVILIZACIONES MEDITERRÁNEAS DE CUARENTA Y CUATRO POSIBLES MUNDIALES}

\begin{tabular}{|c|c|c|c|c|}
\hline Civilizaciones por & $\mathrm{AC}$ & DC & IMPER & \\
\hline $\begin{array}{l}\text { orden de aparición } \\
\text { en el escenario } \\
\text { mediterráneo }\end{array}$ & & & Momento cenital - & Tamaño* \\
\hline 1. Jérico & $9000-1580$ & - & - & - \\
\hline 2. Catal Hüyük & $6500-5800$ & - & - & - \\
\hline 3. Sumer & $3400-2000$ & - & 2500 a $C$ & $P$ \\
\hline 4. Akkad & $3300-2200$ & - & 2340 a C & $\mathrm{P}$ \\
\hline 5. Egipto & $3250-525$ & - & $\begin{array}{l}3100,2600, \\
1850,1460 \text { a C }\end{array}$ & $\mathrm{P}$ \\
\hline 6. Levante & $2500-1000$ & - & - & - \\
\hline 7. Minos & $2500-1400$ & - & - & - \\
\hline 8. Euroantiguos & $2300-600$ & - & $\begin{array}{l}350,448,447 \\
484,493 \text { d C }\end{array}$ & $\mathrm{P}$ \\
\hline 9. Hitita & $1750-1200$ & - & 1350 a C & $\mathrm{P}$ \\
\hline 10. Babilonia & $1792-1595$ & - & 1770 a $\mathrm{C}$ & $\mathrm{P}$ \\
\hline 11. Micenas & $1500-1300$ & - & - & - \\
\hline 12. Israel & 1260-hoy & - & 960 a C & $\mathrm{P}$ \\
\hline 13. Asiria & $1200-612$ & - & 1210,639 a C & $\mathrm{P}$ \\
\hline 14. Fenicia & $1000-574$ & - & 850,216 a C & $\mathrm{P}$ \\
\hline 15. Hélade & 900 & 30 & $\begin{array}{l}452,404,338 \\
325 \text { a C }\end{array}$ & $3 \mathrm{P}, 1 \mathrm{G}$ \\
\hline 16. Etruria & $800-300$ & - & - & - \\
\hline 17. Roma & 753 & 476 & $180 \mathrm{~d} C$ & $\mathrm{G}$ \\
\hline 18. Persia & 550 & 650 & $\begin{array}{l}585,485 \\
100 \text { a C }\end{array}$ & $2 \mathrm{P}, 1 \mathrm{G}$ \\
\hline 19. Bizancio & - & $330-1453$ & $560 \mathrm{~d} C$ & G \\
\hline 20. Islám & - & 622-hoy & $800,1672 \mathrm{~d} \mathrm{C}$ & G \\
\hline $\begin{array}{l}\text { 21. Eurocristiana } \\
\text { medieval }\end{array}$ & - & $650-1500$ & $\begin{array}{l}800,962 \\
1338 \mathrm{~d} \mathrm{C}\end{array}$ & $2 \mathrm{P}, 1 \mathrm{G}$ \\
\hline $\begin{array}{l}\text { 22. Eurocristiana } \\
\text { moderna }\end{array}$ & - & $1450-1776$ & $\begin{array}{l}1525,1571,1700 \\
1709,1713 \mathrm{~d} \mathrm{C}\end{array}$ & $2 \mathrm{P}, 3 \mathrm{G}$ \\
\hline $\begin{array}{l}\text { 23. Occidental y } \\
\text { mediooriental }\end{array}$ & - & 1776-hoy & $\begin{array}{l}1798 \text { a C } \\
1973 \text { d C }\end{array}$ & $2 \mathrm{P}, 11 \mathrm{G}$ \\
\hline
\end{tabular}

*P: pequeño; G: grande

Fuente: Prof. Benjamín Oltra. Programa de Sociología y Cultura del Mundo Mediterráneo, Dpto. de Sociología I, Universidad de Alicante; y Fundación Ciencias Sociales y Mundo Mediterráneo, Altea. 


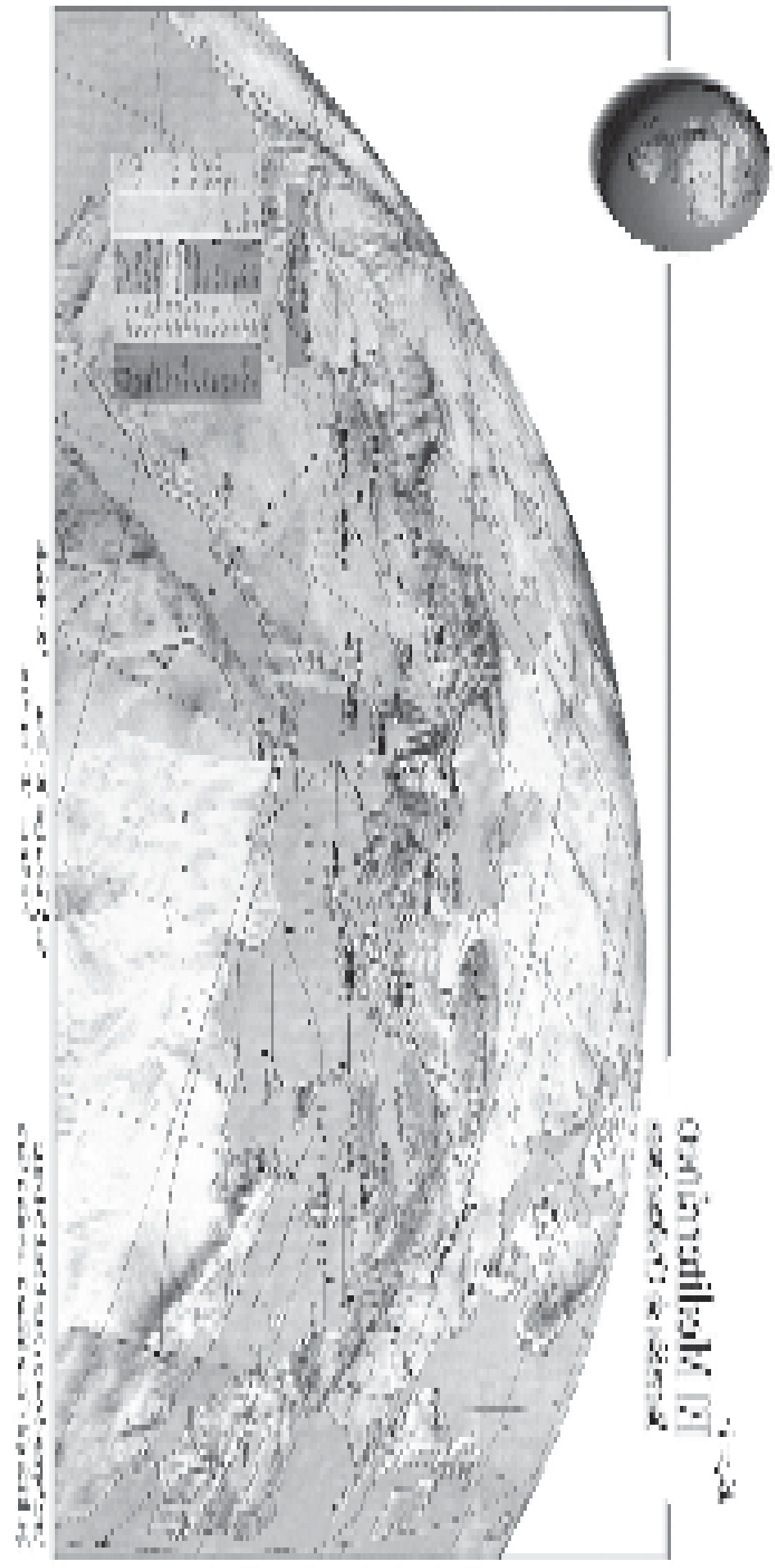


Hablamos, párense mientes, de un tiempo vivo, no de mero archivo del pasado o de una suerte de cementerio; un tiempo palpitante en el sentido de que nosotros venimos de él y nosotros lo investigamos, lo leemos, lo admiramos, viajamos por sus aguas y rincones y, por tanto, lo hacemos de mil maneras revivir. Ese vector que, como sugirió Freud, tiende hacia Eros, está representado literaria y artísticamente en un río de civilizaciones que ha dado paso a la civilización occidental, entre otras, y, a partir de ella, ha hecho posible la llegada a las sociedades, como sugiero, sistemas de convivencia en los que es posible, en términos relativos, la paz, el bienestar, la democracia, el pluralismo cultural, la educación y la vida como personas libres y como ciudadanos; un sistema que podemos dibujar, desde la teoría de los juegos de Von Neumann, como de suma positiva o cooperativa que, naturalmente, incluye subsistemas de suma cero que crean pobreza, desgracia y guerra. ¿Cómo ha sido simbolizado y vivido ese mundo?. Hay, según yo lo veo, cuatro maneras esenciales:

Adagio: "herrlichen Namen", tal como cantara Hölderlin en Der Archipielagus

Primera. El Mediterráneo como hierofanía y mito, del griego hierós, sagrado y phanós( a su vez de phaíno), manifestación, expresión de lo sagrado; y mýthos, leyenda. Relato divino, fabuloso y fabulador, leyenda, alegoría y mitología, el Mediterráneo, de antiguo, ha estado plasmado en el panteón de sus dioses, la epopeya de sus héroes, el acervo de sus criterios sobre lo bello, lo bueno, lo verdadero, lo virtuoso, lo justo, lo sagrado, lo útil, la felicidad, el amor, la vida, la muerte, el tiempo, en definitiva el ser, y sus contrarios. En la revelación y la mística, en la metafísica y la filosofía, en la ciencia y las artes, en la conciencia colectiva, se crean, y se transmiten, en los templos, poleis, hogares, ágoras, mercados, academias, liceos, jardines, abadías, universidades, sectas y círculos invisibles, toda esa pléyade de ideas y valores literaturizadas en forma de narraciones fabulosas con el fin de establecer el origen, evolución y proyección de la naturaleza, el hombre, la sociedad y la divinidad. De semejante laberinto de mitos, de esa mitología, brotan los distintos mediterráneos míticos: el teomórfico de la Odisea (Poseidón, dios de las aguas y Mediterráneo mismo); el heroico de la Iliada (Aquiles, Hector) y la Eneida (Eneas); el fenicio (la reina Dido); el de la ciudadanía griega y romana; el de la sobriedad áurea horaciana; el epicúreo, el estoico, el hedonista; el veterotestamentario, neotestamentario y coránico; el renacentista y humanista, etcétera; preciados mitos eficazmente aculturadores, forjadores de grandes vigencias de simbolismo, sentido y significado.

Segunda. El Mediterráneo como metáfora, del griego metafora, del latín metaphora, llevar más allá, transcender.¿Cómo? Sub specie literaturae. Es la consecuencia del mito, del arquetipo. Se plasma el mito en figura literaria que responde perfectamente al mundo real, pero en otras claves lingüísticas. Es lo que hizo Homero en la Odisea y en la Iliada. Por eso no le fue difícil a Schlieman, Iliada en mano, 
descubrir Ilión, o Troya, ese inmenso yacimiento de sueños, muros y tesoros; ni a Bradford, con la Odisea convertida en carta náutica, surcar las aguas, tras las desdibujadas huellas de Ulises y concluir que el poema es un fascinante documento náutico metafórico. Los antiguos, es sabido, consideraban sagrada y humana a la naturaleza. El auténtico mito se plasma en metáfora. En fin, Calipso, el centro mismo del omphalos cosmou (ombligo del mundo), donde la diosa retiene a Ulises, es Malta, la secular Melite, la isla de miel. Los cíclopes, los lestrigones, los lotófagos de la preciosa Djerba, Scilla y Caribdis, son, según el fiel Bradford, volcanes, fenómenos terrestres y marinos reales expresados en inigualables metáforas. Así, persistentemente, aparece el Mediterráneo como sustancia literaria, además de en los poemas homéricos, en la Teogonía, Olímpicas, Diálogos, Política, en la llamada «sabiduría griega», compuesta por los mitos metaforizados de Diónisos, Apolo,Eleusis, Orfeo, Museo, los Hiperbóreos y Enigma, en la Orestiada, Edipo, Medea, Las Ranas, Las Argonáuticas, Las Metamorfosis, las Odas horacianas, La Eneida, El Apocalipsis, La Civitas Dei, la Summa Theologica, la Commedia, Al Muqqadimah, El Príncipe, los Sonetos petrarquinos, la Poesía de San Juan de la Cruz, El Archipiélago de Hölderlin, los Sonetos a Orfeo de Rilke, L'apres midi d'une faune de Mallarme, Le cimetière marin de Valéry, el poema «Itaca» de Kavafis, el Ulises de Joyce, por citar sólo algunas memorables obras de la infinita fuente de la creación mediterránea. En este insólito contexto se entiende por qué Freud dijo, en Das Unbehagen in der Kultur (1930), que la cultura es un vector creativo que tiende hacia Eros.

Tercera. El Mediterráneo como utopía, del griego ou topos, no lugar. Cierto, salvo el paraíso. Y el paraíso estuvo siempre cerca o en el Mediterráneo. En Mesopotamia o en alguna de las islas de la guirnalda que extrañamente teje Chipre con Tabarca. Hay, como es sabido, varios tipos de utopías: la tierra prometida y la venida del Mesías, la urbs Ierusalem beata, la civitas Dei de San Agustin, las comunidades descritas por Bacon y Moro, los falansterios de Fourier, la sociedad sin clases de Marx; mas el Mediterráneo es un objeto de deseo utópico, un espacio-tiempo utópico de primera magnitud. El clasicismo, la polis, los órficos, las Bucólicas y las Geórgicas de Virgilio, la «aurea mediocritas» horaciana del Beatus Ille, la promesa de las tres religiones monoteístas del Libro, la gnósis, los apocalípticos, las diversas corrientes subterráneas que mezclan modelos y organizaciones de inspiración hemética y heterodoxa en el mundo egipcio, en el helenismo, en las formas heréticas medievales, en el milenarismo, en la alquimia, la ciencia y el humanismo, en el Barroco, el Iluminismo, el Romanticismo, hasta llegar a las sociedades del bienestar actuales y al hedonismo actual como velada forma de negocio y trivial estilo de vida, en fin, el tradicionalismo y el progresismo ingenuos y, desde luego, ciertas modalidades de turismo. Todas estas ideologías surgen, en buena medida, del Mediterráneo, y construyen utopías, retroutopías y antiutopías que tienen que ver con el mare internum nostrum.

Cuarta. El Mediterráneo como agonía, del griego agon. Expresa la lucha como tensión creadora para morir y renacer. Un escenario de conflicto, traumas, luchas y guerras sin fin es el Mediterráneo. Desde siempre. Estamos ante el otro polo de 
Eros, Tánatos, la aniquilación, en este caso sin literatura, aunque ella haya dado muy bellas páginas de sangre, despedazamiento y muerte. En los últimos versos de la Eneida, Eneas hunde su espada en el pecho de Turno invocando la venganza del joven Pallante y desoyendo la súplica de un Turno en situación límite. Cumplida la estocada, sus miembros desfallecen de frío. Virgilio concluye:

«vitaque cum gemitu fugit indignata sub umbras».

Y la vida, con un gemido, huyó indignada bajo las sombras. No hay verso igual a éste en toda la historia de la Literatura universal. Es esta una irrepetible imagen de la agonía, pero hay otras que todavía palpitan en una apocalíptica historia de no menos de 33 guerras, largas, inter-nacionales y devastadoras, desde hace 5100 años, en Egipto, hasta la últimas guerras infames de Bosnia y Kosovo y el terror en Israel y Argelia. Luchan, ciertamente, en el Mediterráneo, los dioses, los hombres, los pueblos, las ciudades, los estados, las religiones y la naturaleza. Luchan con un conflicto de valores, de intereses y de odios, dijérase que radical. Pareciera como si a tanta cultura, a tan grande ambición, a tan implacable pulsión de Eros, les faltara el espacio y el agua. Heráclito dijo, hace aproximadamente 2500 años: 'Pólemos pánton men páter ésti, pánton de basileus", "la guerra es el padre de todo, el rey de todo"(Diels- Kranz, Die fragmente der Vorsokratiker, frag. 53).

Entonces el argumento parece perfilarse. Hay un Mediterráneo épico, de los dioses y de los héroes; un Mediterráneo lírico y dramático de los artistas; un Mediterráneo trágico de los pensadores, la economía, la política, la vida, la guerra y la muerte; y un Mediterráneo sabio del arte de vivir y las formas civilizadas y sociales. En el Mediterráneo, literatura y géneros son su vida y acontecer.

\section{Allegro bárbaro: nuestra época}

El Mediterráneo dio vida y sentido fecundos a Oriente y Occidente, y ambos lo transformaron en el trágico escenario del siglo XX. En él ya nada será igual que en el pasado. Séneca lo había anunciado, allá por el año 60 de nuestra era, en su Medea, en plena melancolía y con precisa lucidez:
"Ahora los mares se sienten vencidos
y aceptan las leyes que dictan los hombres.
No es ya necesaria la célebre nave
de remos potentes movidos por reyes,
que fue construida por mano de Palas.
Ya cualquier barquilla recorre el abismo,
han sido alterados del orbe los lindes,
y en tierras recientes se alzaron ciudades.
El mundo, patente, ya nada conserva
donde lo produce.
Ya beben los indios del frígido Araxes; 
del Rin y del Elba beben ya los persas.

Pasados los años vendrán tiempos nuevos:

soltará el océano los lazos del orbe,

y un gran continente saldrá de las olas,

y Tetis la gloria verá de otros mundos.

Y entonces la tierra no acabará en Tule."

(Trad. de Valentín García Yebra)

Tule era Finisterre, por el sur, e Islandia, por el norte. Se establecieron, en efecto, en el siglo XX, dos estructuras históricas mal vertebradas; de un lado los viejos cleavages, divisorias religiosas, étnicas, nacional-culturales, políticas, económicas, de clase, ideológicas; de otro, las estructuras políticas modernas, los estados y los imperios. Demasiadas fisuras puestas por «la Historia» reaparecen hoy en forma tribal- nacionalista- guerrera y/o en forma religiosa fanática. Como viera el genio de Max Weber para Occidente, se desacraliza y desencanta el mundo mediterráneo y, paralelamente, se torna una pequeña «resolución» fractal, infinitamente compleja y de una rara belleza y exhuberancia explotada y trivialmente presentada por cierto sector del negocio turístico. Ese pequeño gran mundo forma ya parte del complejo ajedrez del orden mundial. En nuestro Mapa 2 (El Mediterráneo: Civilizaciones y Estados) y en los Cuadros 2 (Modelo geoeconómico, político y cultural...) y 3 (Estados mediterráneos con fisuras), presento un modelo realista de los países mediterráneos actuales ( 22 grandes, 4 singulares) con sus características de pluralismo u homogeneidad cultural, estado parlamentario o presidencialista, influencia o no de la religión en el estado y en la sociedad, tipos de economía, transición o no de la población, tipo de fecundidad, emisión o recepción de migrantes y tipo de fisuras, nacionalistas, religiosas e internacionales. El resultado, en relación con las variables estructurales mencionadas, son siete Mediterráneos: (1 y 2) al suroeste y este (de Marruecos a Egipto), el árabe-bereber islámico (el Magreb, la tierra donde se pone el sol, y el Masriq o Levante), con sus diversas variantes religiosas, económicas, políticas y de clases y liderazgo. (3) Al extremo sureste, Israel, con el problema palestino, encarrilado, hace tres años por Rabin y Arafat, con el pacto de Taba, y hoy descarrilado, con el péndulo en el otro extremo debido a los diversos actores fundamentalistas y la política de gobiernos israelíes, con la enemiga de Siria, con la espina clavada de los Altos del Golán y su decidido apoyo a Hamás y la Yihad Islámica. (4) Al extremo noreste, Turquía, a la sombra imponente del Imperio Otomano, con el doble problema kurdo y fundamentalista, (5) al lado de una Hélade geoculturalmente emplazada en la civilización ortodoxa pero, como sociedad, integrada en la Unión Europea. (6) Al norte centroriental los nuevos volcánicos Balcanes, el fractal mediterráneo adriático donde colisionan las tres "placas tectónicas", católicos croatas, bosnios musulmanes y serbios ortodoxos, con enrevesadas combinaciones en Bosnia-Herzegovina y Yugoslavia, con el cabo del problema macedonio-griego y la menesterosa perplejidad de Albania, en el 
transfondo de una historia de pueblos encontrados en un territorio sojuzgado que se remonta a los primeros siglos de nuestra era. Y (7) en el norte occidental, los tres países de la Unión Europea del sur, con Malta (la vieja centrada y ensimismada isla de Calypso de la Odisea) y Grecia, oriental y ortodoxa, con el bello espectro al fondo de ser la estrella del Mediterráneo, y ahora unida a la nueva unión cristiana, democrática, desarrollada y secular.

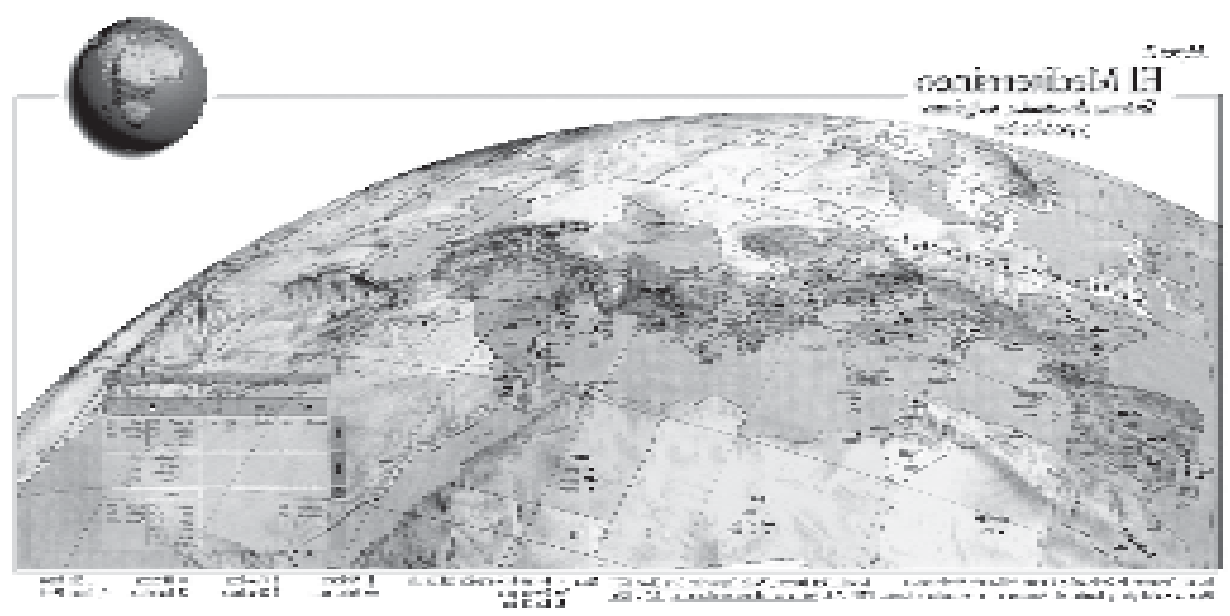

Fuente: Prof. Benjamín Oltra. Programa de Sociología y Cultura del Mundo Mediterráneo. Dpto. de Sociología I, Universidad de Alicante; y Fundación Ciencias Sociales y Mundo Mediterráneo, Altea. 


\section{MODELO GEOECONÓMICO - POLÍTICO - CULTURAL DEL MEDITERRÁNEO}

OESTE

*Ciencia; pluralismo cultural; catolicísmo.

*Estado y sociedad del bienestar *Economía en transición

*Democracia liberal parlamentaria *Regímenes presidencialistas

*Muy baja fecundidad, transición*Baja y media fecundidad

Demográfica

*Receptores de familias de

inmigrantes del sur y del este
*Emisores de emigrantes
ESTE

$\begin{array}{ll}\text { *Ortodoxia } & \text { *Islamismo } \\ \text { *Pluralismo cultural } & \text { *Homogeneidad } \\ \text { *Estado del Bienestar } & \text { cultural } \\ \text { *Baja fecundidad } & \text { *Economías en } \\ & \text { desarrollo } \\ & \text { *Fecundidad } \\ & \text { media } \\ & \text { *Emisor de } \\ & \text { emigrantes }\end{array}$

\author{
emigrantes \\ *Islamismo \\ *Economías en \\ desarrollo \\ *Fecundidad \\ media
}

Francia (UE)
Italia (UE)
España (UE)
Portugal (UE)
Malta
..................... Turquía

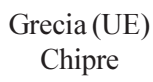

Eslovenia

Croacia

Bosnia-Herzegovina

(postguerra)

Yugoslavia

(guerra)

Macedonia

Albania
*Islamismo, homogeneidad cultural

*Economías en desarrollo

*Regímenes presidencialistas y

autocráticos

*Alta fecundidad

*Emisores de emigrantes al Norte

*Islamismo
*Homogeneidad cultural
*Economías en desarrollo
*Regímenes presidencialistas
*Alta fecundidad
*Emisores de emigrantes

Egipto

Jordania

Líbano

Siria
*Judaísmo

*Pluralismo cultural

*Ciencia

*Economía en relativo desarrollo

*Democracia Parlamentaria

*Fecundidad media

* Receptor de inmigrantes

\section{Marruecos \\ Argelia \\ Libia}

Israel

Fuente: Prof. Benjamín Oltra. Programa de Sociología y Cultura del Mundo Mediterráneo, Dpto. de Sociología I, Universidad de Alicante; y Fundación Ciencias Sociales y Mundo Mediterráneo, Altea.

Este mapa estructural y cultural es un mapa de fisiones, como puede apreciarse, pero también un mapa de cooperación futura, si se dan ciertas condiciones. El Mediterráneo es un añoso, dramático y creativo conjunto o sistema ecosociopolítico en el que se amalgaman culturas y civilizaciones, como la cristiana y secular, que han fructificado en las sociedades, en el norte occidental, con Grecia en el norte oriental, con civilizaciones como la hebrea de Israel, la tierra sagrada de 
Moisés y Jesús cuyo centro es Jerusalén, la urbs Ierusalem beata para judíos, cristianos y musulmanes, pero que para ser una sociedad acabada le falta la paz, con civilizaciones, como el Islám, indeciso entre el despotismo y las sociedades.

En esta a manera de «matriochka» repleta de más pequeñas «matriochkas» contrapuestas; en este orden heracliteano, con la guerra como «padre» y "rey"; en esta suerte de mundo «taoísta», en versión mediterránea, con su yang/yin intercambiable; en esta cultura de culturas y civilización de civilizaciones; en este «mare conclusum», infinito y recoleto, al mismo tiempo, contaminado y saludable(con capacidad de renovación como ser vivo), la otra cara de la realidad son varios procesos esperanzadores, frágiles, complejos, en el filo de la espada del conflicto, pero con su futuro: en primer lugar los programas de ayuda, cooperación y desarrollo de la UE y sus posibles consecuencias positivas en el sur y este; en segundo lugar, el efecto futuro, a largo plazo, de los acuerdos de paz y pacificación entre Israel y la Autoridad Palestina, con el transfondo de una actitud de reconocimiento y positiva del mundo árabe, salvo Siria; en tercer lugar, el redescubrimiento ambiental, arqueológico, histórico, sociológico y cultural del Mediterráneo, con todas sus civilizaciones y culturas, en el último siglo, con efectos muy positivos en la investigación y en los encuentros de diálogo entre las tres civilizaciones herederas actuales de ese mundo; en cuarto lugar, las posibles implicaciones de cooperación política y económica entre los distintos fragmentos presentados en el mapa de siete Mediterráneos; en quinto lugar, la conciencia de crisis medioambiental, la investigación científica en Ecología y los programas de acción en el Mediterráneo.

¿Cómo definir este complejo mundo mediterráneo con el Logos y el Pathos como argumento? Mi respuesta es: con una nueva areté, valor, vigor o virtud aprendida en la belleza de sus páginas, ciudades, ruinas, paisajes, tierras y en sus aguas. El Mediterráneo es un insólito precipitado cultural, civilizatorio y ambiental fruto de la historia dialéctica de 26 civilizaciones en el transfondo mundial de 46 significativas. La síntesis visual de todo este majestuoso curso civilizatorio nos la ofrece la imagen del Mapa 1. Ese río histórico, ese Nilo nutriente, en forma de mar interior, es un prisma que presenta facetas que se reflejan y crean con una luz especial; facetas específicas en sus originales civilizaciones; fuente creativa incesante en su sabiduría, artes, ciencias, filosofías, religiones, cosmovisiones y estilos de vida; modelos productivos con variantes del capitalismo, economías informales y posibles formas cooperativas; modelos políticos originales en la polis, los imperios, los estados; y episodios destructivos y de desigualdad que hemos mencionado. La imagen de la que uno puede servirse para elaborar una teoría narrativa que parta de la hipótesis de que el Mediterráneo tiene su sentido en las sociedades actuales, y que de él puede manar la energía de su cooperación y bienestar, es la del Ave Fénix que puede recomenzar, como la mar. El Mediterráneo es cultura, civilización y sociedad reiterada y renovada. Además.... es tan bello. 


\section{Final: esperar sembrando}

En el ánfora de Pandora, del que, a veces, salen muchas de nuestras tragedias, recuérdese que la última es siempre la esperanza. El arte de esperar sembrando, permítanme esta licencia poética, alimenta estas modestas ideas que son algunas de las líneas de trabajo de la Fundación de "Ciencias sociales y Mundo Mediterráneo" creada en 1997, en la ciudad alicantina de Altea. La institución es una joint venture, cooperativa y sin ánimo de lucro, fundada por iniciativa del ayuntamiento de Altea y varios profesores de nueve Universidades de España, Francia e Italia. El trabajo de la Fundación consiste, en primer lugar, en el desarrollo de un programa de investigación que explora sistemáticamente, en detalle y en su conjunto y desde la óptica de varias disciplinas, cómo a lo largo de la dilatada duración de unos once mil años, el Mediterráneo contempla en su seno nutriente el paso de antiquísimas y fecundas, mas también frágiles, culturas, a las civilizaciones hoy prestigiosas, pero sólo parcialmente conocidas, y, desde este inmenso latido civilizatorio, el tránsito a las sociedades y estados actuales, ciertamente agobiados por los problemas de todos conocidos, aunque, si se observa con mirada profunda y limpia a las sociedades civiles y a los ciudadanos, llenas de potencialidades y de futuro. La Fundación ofrece su trabajo en forma de investigación permanente, de asesoramiento y de informes sobre materias diversas y concretas que analizan problemas reales. En segundo lugar, la investigación vierte su cosecha en un archivo informático de documentación compuesto por datos estadísticos, textos, imágenes y documentos visuales y sonoros sobre veintitrés civilizaciones y veintiséis estados, a lo largo de once mil años. Venimos trabajando, en tercer lugar, en la organización y puesta en escena anual de un seminario de alta formación interuniversitaria, rara avis en nuestra vida universitaria. Hasta la fecha se han impartido cuatro cursos, desde 1997 hasta el presente. Este tipo de actividad académica es vital para estudiantes maduros, para recién licenciados y para todo tipo de profesionales y ciudadanos, en definitiva para aquellas personas a las que la cultura y, particularmente el mundo mediterráneo, sea el leitmotiv y la textura de su vida.

La Fundación proyecta llevar a cabo otras actividades de comunicación social, de organización de viajes culturales y de estudio, de publicación de obras útiles a la ciudadanía; de contribución, en fin, a la información, educación continuada, libertad y bienestar colectivo de adultos y jóvenes de nuestros Alicante, Comunidad Valenciana, España, el Mediterráneo, Europa y el vasto y necesario mundo; y todo ello desde una ciudad mediterránea pura, la estética y renovada ciudad de Altea. 